CLINICAL STUDY

\title{
Umbilical cord levels of sclerostin, placental weight, and birth weight are predictors of total bone mineral content in neonates
}

\author{
Kristin Godang $^{1}$, Kathrine Frey Frøslie ${ }^{2,3}$, Tore Henriksen ${ }^{4,5}$, Gunhild A Isaksen ${ }^{1}$, Nanna Voldner ${ }^{4}$, Tove Lekva ${ }^{1,6}$, \\ Thor Ueland ${ }^{6}$ and Jens Bollerslev ${ }^{1,5}$ \\ ${ }^{1}$ Section of Specialized Endocrinology, Department of Endocrinology, Oslo University Hospital Rikshospitalet, PO Box 4950 Nydalen, Oslo 0424, Norway, \\ ${ }^{2}$ Department of Biostatistics, Institute of Basic Medical Sciences, University of Oslo, Oslo, Norway, ${ }^{3}$ Norwegian Resource Center for Women's Health, Oslo \\ University Hospital, Oslo, Norway, ${ }^{4}$ Division of Obstetrics and Gynecology, Oslo University Hospital Rikshospitalet, Oslo, Norway, ${ }^{5}$ Faculty of Medicine, \\ University of Oslo, Oslo, Norway and ${ }^{6}$ Faculty of Medicine, Research Institute for Internal Medicine, University of Oslo, Oslo, Norway
}

(Correspondence should be addressed to K Godang; Email: kgodang@ous-hf.no)

\begin{abstract}
Context: During pregnancy, changes occur in the maternal calcium homeostasis to fulfill fetal demand. We hypothesized that the fibroblast growth factor 23 (FGF23) system and Wnt signaling pathway are important for normal skeletal development in the offspring.

Aims: Circulating $\alpha$-klotho, FGF23, sclerostin, and 25-hydroxyvitamin D (25(OH)D) at the fetal and maternal sides of the placenta were measured to investigate associations with newborn bone mass independent of maternal BMI, calcium and phosphate levels, placental weight, and birth weight. Methods: In a prospective cohort of healthy pregnant women, the total body bone mineral content (BMC) in 202 newborns was measured by dual-energy X-ray absorptiometry. Maternal circulating levels of the biomarkers were measured at gestational weeks 30-32 and in umbilical cord plasma (UCP) at birth.

Results: Mean $\alpha$-klotho and sclerostin concentrations in the UCP were significantly higher than maternal levels (3004 vs $1077 \mathrm{pg} / \mathrm{ml} ; P<0.001$ and $629 \mathrm{vs} 346 \mathrm{pg} / \mathrm{ml} ; P<0.001$ respectively), and mean 25(OH)D was lower (31 vs $45 \mathrm{nmol} / \mathrm{l} ; P<0.001$ ). The UCP and maternal FGF23 levels were similar. No significant effects of maternal biomarkers on BMC were found in regression analyses. Among UCP biomarkers, only UCP sclerostin was significantly associated with BMC in univariate analyses, and the effect remained significant after adjustment for birth weight and other confounders. Conclusions: We found that UCP sclerostin levels, birth weight, and placental weight were significant predictors of neonatal BMC but found no evidence for a main role of maternal levels of $\alpha$-klotho, FGF23, sclerostin, or 25(OH)D nor of UCP levels of $\alpha$-klotho, FGF23, or 25(OH)D.
\end{abstract}

European Journal of Endocrinology 168 371-378

\section{Introduction}

During pregnancy, significant changes occur in the maternal bone metabolism and calcium homeostasis to fulfill the fetal demand for calcium. Adequate mineralization of the skeleton relies on the following three related parameters: maternal food intake, the function of the placenta, and the ability of the fetus to use the nutritional supplies (1).

The regulation of maternal placental-fetal mineral homeostasis and skeletal development has remained largely unknown. Generally, there are increases in both the calcium absorption from the gut and bone resorption in the mother to meet the demand for calcium transfer to the growing child. Maternally regulated cytokines and hormones might influence the placental to fetal calcium transport by influencing the ambient maternal blood calcium levels and by a direct effect on the placental function (2). Calcium is actively transported across the placenta, and the fetal serum calcium and inorganic phosphate $(\mathrm{Pi})$ levels are higher than those on the maternal side $(3,4)$.

Biochemical markers of the maternal bone turnover indicate that bone remodeling is low during the first half of the pregnancy and may increase in the third trimester $(5,6,7)$. Fibroblast growth factor 23 (FGF23) is expressed predominantly in osteoblasts and osteocytes (8). Recent observations suggested that FGF23 is a potent hormonal factor that regulates inorganic $\mathrm{Pi}$ and 1,25-dihydroxyvitamin $\mathrm{D}_{3}$ (9). However, the role of FGF23 protein in neonatal mineral homeostasis is unknown. A previous study suggested that FGF23 might significantly influence the $\mathrm{Pi}$ homeostasis in healthy term infants (10). FGF23 binds to its receptor together with the obligatory co-receptor, $\alpha$-klotho, which is expressed in other tissues including the placenta (11). Notably, $\alpha$-klotho appears to be predominantly expressed in syncytiotrophoblasts with 
some expression in the endothelium of fetal vessels (12). If the syncytiotrophoblasts can secrete and activate fetal $\alpha$-klotho, it could contribute to elevated levels of $\alpha$-klotho which would be found in the umbilical cord plasma (UCP).

Multiple studies have demonstrated a pivotal role of the Wnt signaling pathway for bone development, mass, and structure $(13,14)$. Recently, the importance of the osteocyte product sclerostin for regulation of the Wnt pathway was established based on genetic studies of patients with high bone mass (15). Sclerostin is a glycoprotein that inhibits osteoblast differentiation and bone formation (16). Although the underlying mechanisms are unclear, it was hypothesized that sclerostin has an inhibitory effect on bone formation by directly blocking the Wnt signaling pathway (17). Thus far, the sclerostin levels have not been investigated in the placenta or in human newborns.

We have recently established a cohort of welldescribed normal newborn babies (18) who were recruited from a prospective study of normal pregnancies, the STORK study (19). We hypothesized that the FGF23 system and the Wnt signaling pathway are important for the development of a normal skeleton in newborn babies. The aims of this study were to determine the circulating levels of $\alpha$-klotho, FGF23, sclerostin, and 25-hydroxyvitamin $\mathrm{D}_{3}(25(\mathrm{OH}) \mathrm{D})$ at the fetal and maternal side of the placenta and to test whether these variables were related to the newborns' bone mass independent of the mothers' early pregnancy BMI, maternal circulating levels of calcium and $\mathrm{Pi}$, the placental weight, and birth weight.

\section{Materials and methods}

The present work was performed in a subsample of the STORK study (19). STORK is a prospective cohort study of healthy women with Scandinavian heritage who registered for obstetric care at Oslo University Hospital Rikshospitalet, from 2001 to $2008(n=1031)$. The exclusion criteria were multiple pregnancies, known pre-gestational diabetes, and severe chronic diseases (lung, cardiac, gastrointestinal, or renal). The women were scheduled for four antenatal visits at gestational weeks $14-16,22-24,30-32$, and 36-38. The maternal height (self-reported) was obtained at the first visit, and the weight was measured at each visit. The BMI was calculated as weight (in kilograms) divided by height (in meters) squared. In the analyses, only the BMI from the first visit was used as this was the best estimate for the women's normal or pre-gestational body composition. At birth, measurements of birth weight and placental weight were recorded.

We invited 234 women from the cohort and their babies (2005-2008) to participate in a substudy of the newborns' total bone mineral content (BMC) as measured by dual-energy X-ray absorptiometry
(DXA) (18). Women with a preterm birth, defined as $<37$ weeks of gestation, were excluded before the analyses (20). This resulted in a study sample of $n=202$ (Fig. 1).

For the DXA analyses, a narrow fan-beam GE Lunar Prodigy Densitometer (GE Medical Systems, Lunar Corp., Madison, WI, USA; software version 12.10) was used. The total body BMC and total body bone mineral density (BMD) were measured. The scanning procedure has been described in detail previously (18). According to the manufacturer, the coefficients of variation $(\mathrm{CV} \%)$ for the Lunar DPX-L instrument (regarded by the manufacturers to be similar to the Lunar Prodigy) is $1.1 \%$ for the total body BMC (21).

\section{Ethics}

The study was approved by the Regional Ethics Committee and performed according to the Declaration of Helsinki. All women provided written informed consent.

\section{Biochemical variables}

The maternal circulating levels of $\alpha$-klotho, FGF23, sclerostin, and $25(\mathrm{OH}) \mathrm{D}$ were measured in blood samples at gestational weeks 30-32. These measurements were also performed in the UCP. Maternal levels of total calcium, Pi, and fasting glucose were analyzed in blood samples at gestational weeks 30-32.

The maternal blood samples were drawn between 0730 and $0830 \mathrm{~h}$ after an overnight fast. The samples were obtained by a venipuncture into vacutainer tubes. Vacutainer tubes containing EDTA were kept on ice before centrifugation $\left(2500 \mathrm{~g}\right.$ and $4{ }^{\circ} \mathrm{C}$ for $\left.25 \mathrm{~min}\right)$ and the plasma was frozen at $-80^{\circ} \mathrm{C}$ in aliquots within $1 \mathrm{~h}$ of collection until analysis. The umbilical cord blood was collected by the midwife into EDTA tubes, centrifuged for plasma separation, and placed at $-20^{\circ} \mathrm{C}$ for less than a month and stored long term at $-80^{\circ} \mathrm{C}$.

The plasma levels of $\alpha$-klotho and intact FGF23 were measured by two-site ELISA using commercially available kits from Immuno-Biological Laboratories (IBL, Gunma, Japan) and Kainos Laboratories (Tokyo, Japan) respectively $(22,23)$. The plasma levels of

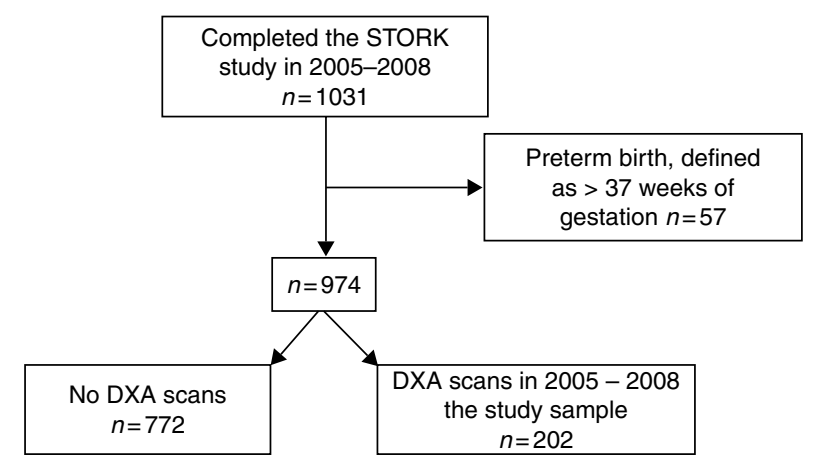

Figure 1 Flow chart showing the selection of the study sample. DXA, dual-energy X-ray absorptiometry. 
sclerostin were analyzed by a 2nd Generation High Sensitive ELISA reagent (Quidel Corporation, San Diego, CA, USA). For this assay, the sensitivity was defined as the lowest standard value, $33 \mathrm{pg} / \mathrm{ml}$. All the samples were analyzed in duplicate from a given mother and her baby in the same microtiter plate to minimize runto-run variability. All samples had detectable levels of sclerostin. Serum 25(OH)D was measured using a RIA from DiaSorin (Stillwater, MN, USA).

All assays were performed according to the manufacturer's instructions. The intra- and interassay CV were $<10 \%$ for all assays. The serum levels of calcium and $\mathrm{Pi}$ were analyzed using standard automatic analyzer techniques at the accredited laboratory at Oslo University Hospital Rikshospitalet, Norway.

The placentas were collected within $1 \mathrm{~h}$ of delivery. The placental weight was measured before cutting the umbilical cord. The tissue samples were snap frozen in liquid nitrogen within $30 \mathrm{~min}$ and stored at $-80{ }^{\circ} \mathrm{C}$.

\section{RNA isolation from placentas}

The samples were pulverized with a mortar in liquid nitrogen, and TRIzol reagent (Invitrogen) was added. The samples were homogenized, and the RNA was purified according to the manufacturer's instructions using a RNeasy micro kit (Qiagen). The integrity was assessed using an Agilent 2100 Bioanalyzer (Agilent Technologies, Santa Clara, CA, USA), and the concentrations were determined by OD readings on a Nanodrop ND-1000 spectrophotometer (Nanodrop Technologies, Wilmington, DE, USA).

\section{Real-time RT-PCR}

RT was performed using a High-Capacity cDNA Archive Kit (Applied Biosystems) with $1 \mu \mathrm{g}$ total RNA. For real-time RT-PCR, sequence-specific oligonucleotide primers were designed using Primer Express software version 2.0 (Applied Biosystems). Primers are available on request.

\section{Gene expression}

The gene expression of FGF23, sclerostin-SOST, $\alpha$-klotho, and $\beta$-actin was measured in tissue samples from two placentas. The gene products of the primers for FGF23 and SOST were validated with other cell types.

\section{Statistical analysis}

Descriptive statistics are presented as the means and S.D. according to the distributional properties of the data. Comparisons of the study sample and the remaining participants in the STORK study with term births were performed by independent sample $t$-tests or Pearson's $\chi^{2}$-tests, as appropriate. Comparisons of the maternal circulating levels of $\alpha$-klotho, FGF23, sclerostin and
$25(\mathrm{OH}) \mathrm{D}$ at gestational weeks $30-32$ and of the same values from the UCP at birth were performed by paired sample $t$-tests.

Estimation of the effects of $\alpha$-klotho, FGF23, sclerostin, and $25(\mathrm{OH}) \mathrm{D}$ maternal circulating levels at gestational weeks 30-32 or UCP levels at birth on $\mathrm{BMC}$ was performed by linear regression analyses, with standardized regression coefficients as the effect measures. The unadjusted and adjusted effect estimates were obtained from univariate and multiple regression analyses respectively.

Multiple linear regression analyses were used to estimate the adjusted effects of $\alpha$-klotho, FGF23, sclerostin, and $25(\mathrm{OH}) \mathrm{D}$ on the BMC after adjusting for potential confounding variables. The analyses were checked for violations of the assumptions in linear regression models.

A $P$ value $<0.05$ was considered statistically significant. All analyses were performed with SPSS version 18.0 (SPSS, Inc., Chicago, IL, USA).

\section{Results}

\section{Cohort characteristics}

Characteristics of the study sample are given in Table 1. The characteristics of the neonates in the study sample were not significantly different from the other neonates born at term in the total STORK cohort, but the pregnant women in this study had a significantly lower BMI at gestational weeks 14-16 (data not shown).

Table 1 Sample characteristics of the pregnant women and their infants.

\begin{tabular}{|c|c|c|c|}
\hline & $\begin{array}{c}\text { Women } \\
(n=202)^{\mathrm{a}} \\
\text { Mean (S.D.) }\end{array}$ & $\begin{array}{c}\text { Infants } \\
(n=202)^{\mathrm{a}, \mathrm{b}} \\
\text { Mean (S.D. })\end{array}$ & $P$ values ${ }^{c}$ \\
\hline $\begin{array}{l}\text { BMI (weeks 14-16; } \\
\text { kg/m²; self-reported) }\end{array}$ & $23.9(3.8)$ & & \\
\hline $\begin{array}{l}\text { Gestational age at birth } \\
\text { (weeks) }\end{array}$ & & $40.2(1.2)$ & \\
\hline Placental weight (g) & & 705 (162) & \\
\hline Birth weight $(\mathrm{g})$ & & $3612(480)$ & \\
\hline Scan day (after birth) & & $1.8(1.0)$ & \\
\hline Scan day weight (g) & & 3408 (474) & \\
\hline Total body BMC (g) & & $93(12)$ & \\
\hline $\begin{array}{l}\text { Total body BMD } \\
\left(\mathrm{g} / \mathrm{cm}^{2}\right)\end{array}$ & & $0.345(0.042)$ & \\
\hline Total calcium $(\mathrm{mmol} / \mathrm{l})^{\mathrm{d}}$ & $2.10(0.09)$ & & \\
\hline Phosphate $\left(\mathrm{mmol} / \mathrm{l}^{\mathrm{d}}\right.$ & $1.2(0.2)$ & & \\
\hline$\alpha$-Klotho $(\mathrm{pg} / \mathrm{ml})^{\mathrm{d}}$ & 1077 (586) & 3004 (1353) & $<0.001$ \\
\hline FGF23 $(\mathrm{pg} / \mathrm{ml})^{\mathrm{d}}$ & $263(115)$ & $255(125)$ & 0.25 \\
\hline Sclerostin $(\mathrm{pg} / \mathrm{ml})^{\mathrm{d}}$ & 346 (153) & $629(295)$ & $<0.001$ \\
\hline $25(\mathrm{OH}) \mathrm{D}(\mathrm{nmol} / \mathrm{l})^{\mathrm{d}}$ & $45(18)$ & $31(18)$ & $<0.001$ \\
\hline
\end{tabular}

BMC, bone mineral content; BMD, bone mineral density; FGF23, fibroblast growth factor 23; $25(\mathrm{OH}) \mathrm{D}, 25$-hydroxyvitamin $\mathrm{D}_{3}$.

${ }^{a} n$ may vary due to missing values.

${ }^{b}$ Born at term, defined as birth at gestational week 37 or later.

${ }^{\mathrm{c} C}$ Comparison of maternal and neonatal values.

dMaternal values are obtained from blood samples at gestational weeks 30-32. 


\section{Circulating levels of $\alpha$-klotho, FGF23, sclerostin, and $25(\mathrm{OH}) D$}

The mean $\alpha$-klotho and sclerostin concentrations in the UCP were significantly higher than the mean maternal circulating levels (3004 vs $1077 \mathrm{pg} / \mathrm{ml} ; P<0.001$ and 629 vs $346 \mathrm{pg} / \mathrm{ml} ; P<0.001$ respectively), and the mean $25(\mathrm{OH}) \mathrm{D}$ concentration in UCP was significantly lower than in maternal circulation (31 vs $45 \mathrm{nmol} / \mathrm{l}$; $P<0.001$; Table 1 and Fig. 2). The mean FGF23 concentration in the UCP and the maternal circulating levels were not significantly different (Table 1 and Fig. 2).

\section{Gene expression}

The gene expression of FGF23, sclerostin, and $\alpha$-klotho was analyzed in two placental tissue samples, and we found $\alpha$-klotho to be highly expressed, whereas no gene expression of FGF23 and sclerostin was detected (data not shown).

\section{Analyses of the effect of the maternal circulating levels of $\alpha$-klotho, FGF23, sclerostin, and 25(OH)D on BMC}

Univariate analyses showed no statistically significant associations between the maternal circulating levels of $\alpha$-klotho, FGF23, sclerostin, or $25(\mathrm{OH}) \mathrm{D}$ on the neonatal BMC (Table 2). We used directed acyclic graphs as a regression modeling tool to evaluate the need for adjustments for other variables in the subsequent multiple regression analyses (24). As mentioned below, several variables were considered in the graphs, but variables that were assumed to be predictive for only one of the variables in the above paragraph were left out of the analysis. When in doubt, we included the variables in supplementary analyses.

Based on the literature, we hypothesized that the early pregnancy BMI might influence both the circulating fetal levels of $\alpha$-klotho, FGF23, and sclerostin in late gestation $(25,26)$ and the neonatal BMC $(26,27)$. Thus, BMI was included as a potential confounding variable (28). Maternal circulating levels of calcium, Pi, and $25(\mathrm{OH}) \mathrm{D}$ were included as potential confounders in the analyses, by similar argumentation.

In supplementary analyses, adjustments were also performed for the placental weight by assuming that the placental size at birth reflects the size of the placenta at weeks 30-32 and that the placenta may potentially influence the maternal circulating levels of $\alpha$-klotho, FGF23, sclerostin, or $25(\mathrm{OH}) \mathrm{D}$ and the neonatal BMC. Multiple adjustments did not alter the conclusion of the lack of statistical significance for independent direct effects of the maternal circulating levels of $\alpha$-klotho, FGF23, sclerostin, or $25(\mathrm{OH}) \mathrm{D}$ on the neonatal BMC (Table 2).

\section{Analyses of the effect of the UCP levels of $\alpha$-klotho, FGF23, sclerostin, and $25(\mathrm{OH}) D$ on the BMC}

Univariate analyses revealed no significant associations between the UCP levels of $\alpha$-klotho, FGF23, or 25(OH)D on neonatal $\mathrm{BMC}$, but a significant association between sclerostin and BMC was found (Table 2).
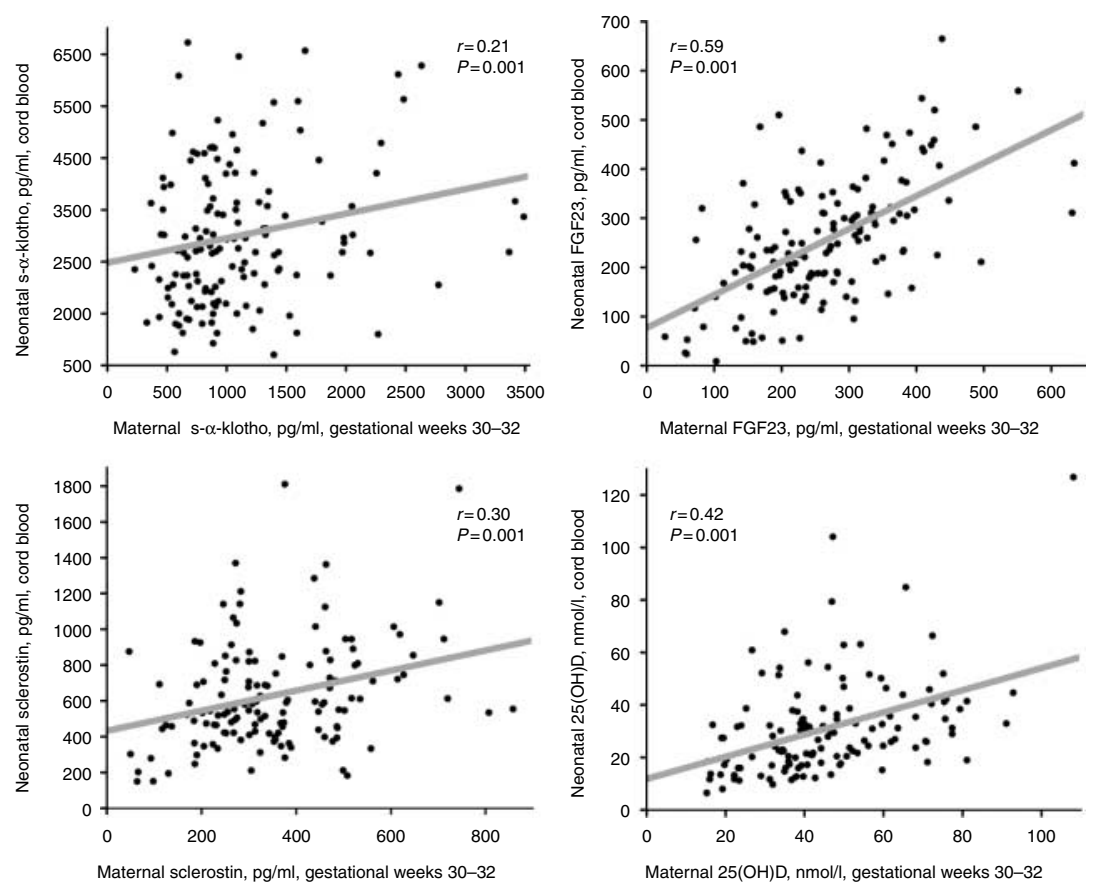

Figure 2 Scatter plots of the correspondence between biomarkers in umbilical cord and maternal plasma. The gray lines represent the best linear fit. Pearson correlation coefficients with corresponding $P$ values are given in each plot. 25(OH)D, 25-hydroxyvitamin D. 
Table 2 Results from the regression analyses of the effect of maternal and UCP levels of $\alpha$-klotho, FGF23, sclerostin, and 25(OH)D on the total BMC in newborns. The variables $\alpha$-klotho, FGF23, sclerostin, and 25(OH)D in maternal circulation and UCP were entered into eight separate regression models, and the table shows the unadjusted and adjusted standardized regression coefficients with $P$ values.

\begin{tabular}{|c|c|c|c|c|c|c|}
\hline & \multicolumn{2}{|c|}{ Univariate } & \multicolumn{4}{|c|}{ Multiple } \\
\hline & $\beta$ & $P$ & $\beta$ & $P$ & $\beta$ & $P$ \\
\hline \multicolumn{7}{|l|}{ Maternal variables } \\
\hline$\alpha$-Klotho (weeks 30-32) & 0.12 & 0.08 & 0.07 & 0.37 & & \\
\hline BMI (weeks 14-16) & & & 0.28 & $<0.001$ & & \\
\hline $25(\mathrm{OH}) \mathrm{D}$ & & & -0.11 & 0.13 & & \\
\hline Calcium & & & -0.04 & 0.57 & & \\
\hline Phosphate & & & -0.02 & 0.83 & & \\
\hline FGF23 (weeks 30-32) & 0.01 & 0.86 & 0.02 & 0.75 & & \\
\hline BMI (weeks 14-16) & & & 0.29 & $<0.001$ & & \\
\hline $25(\mathrm{OH}) \mathrm{D}$ & & & -0.11 & 0.12 & & \\
\hline Calcium & & & -0.04 & 0.56 & & \\
\hline Phosphate & & & 0.00 & 0.96 & & \\
\hline Sclerostin (weeks 30-32) & 0.01 & 0.91 & 0.03 & 0.70 & & \\
\hline BMI (weeks $14-16 ; \mathrm{kg} / \mathrm{m}^{2}$; self-reported) & & & 0.29 & $<0.001$ & & \\
\hline $25(\mathrm{OH}) \mathrm{D}$ & & & -0.12 & 0.11 & & \\
\hline Calcium & & & -0.04 & 0.60 & & \\
\hline Phosphate & & & -0.01 & 0.95 & & \\
\hline 25(OH)D (weeks 30-32) & -0.11 & 0.14 & -0.11 & 0.12 & & \\
\hline BMI (weeks 14-16) & & & 0.29 & $<0.001$ & & \\
\hline Calcium & & & -0.04 & 0.58 & & \\
\hline Phosphate & & & -0.01 & 0.96 & & \\
\hline \multicolumn{7}{|l|}{ Neonatal variables } \\
\hline$\alpha-$ Klotho (UCP) & 0.09 & 0.30 & -0.06 & 0.46 & -0.09 & 0.27 \\
\hline BMI (weeks 14-16) & & & 0.12 & 0.12 & 0.10 & 0.21 \\
\hline $25(\mathrm{OH}) \mathrm{D}(\mathrm{UCP})$ & & & & & 0.12 & 0.13 \\
\hline 25(OH)D (weeks 30-32) & & & -0.04 & 0.59 & & \\
\hline Calcium (weeks 30-32) & & & 0.01 & 0.87 & 0.03 & 0.70 \\
\hline Phosphate (weeks 30-32) & & & -0.01 & 0.95 & -0.03 & 0.74 \\
\hline Placental weight $(\mathrm{g})$ & & & 0.51 & $<0.001$ & 0.50 & $<0.001$ \\
\hline FGF23 (UCP) & -0.07 & 0.42 & -0.09 & 0.21 & -0.11 & 0.16 \\
\hline BMI (weeks 14-16) & & & 0.13 & 0.10 & 0.11 & 0.17 \\
\hline $25(\mathrm{OH}) \mathrm{D}(\mathrm{UCP})$ & & & & & 0.09 & 0.23 \\
\hline 25(OH)D (weeks 30-32) & & & -0.05 & 0.55 & & \\
\hline Calcium (weeks 30-32) & & & -0.02 & 0.85 & 0.01 & 0.92 \\
\hline Phosphate (weeks 30-32) & & & 0.00 & 0.96 & -0.03 & 0.71 \\
\hline Placental weight $(\mathrm{g})$ & & & 0.49 & $<0.001$ & 0.49 & $<0.001$ \\
\hline Sclerostin (UCP) & 0.26 & 0.02 & 0.24 & $<0.001$ & 0.25 & $<0.001$ \\
\hline BMI (weeks 14-16) & & & -0.02 & 0.76 & -0.03 & 0.71 \\
\hline $25(\mathrm{OH}) \mathrm{D}(\mathrm{UCP})$ & & & & & 0.06 & 0.39 \\
\hline 25(OH)D (weeks 30-32) & & & -0.12 & 0.06 & & \\
\hline Calcium (weeks 30-32) & & & 0.05 & 0.39 & 0.07 & 0.29 \\
\hline Phosphate (weeks 30-32) & & & 0.02 & 0.77 & -0.01 & 0.87 \\
\hline Birth weight $(\mathrm{g})$ & & & 0.72 & $<0.001$ & 0.68 & $<0.001$ \\
\hline $25(\mathrm{OH}) \mathrm{D}(\mathrm{UCP})$ & 0.13 & 0.13 & 0.20 & 0.04 & & \\
\hline BMI (weeks 14-16) & & & 0.22 & 0.01 & & \\
\hline Calcium (weeks 30-32) & & & -0.02 & 0.83 & & \\
\hline Phosphate (weeks 30-32) & & & -0.01 & 0.90 & & \\
\hline $25(\mathrm{OH}) \mathrm{D}$ (weeks 30-32) & & & -0.20 & 0.04 & & \\
\hline
\end{tabular}

BMC, bone mineral content; UCP, umbilical cord plasma; FGF23, fibroblast growth factor 23; 25(OH)D, 25-hydroxyvitamin D.

Based on the assumptions that the early pregnancy $\mathrm{BMI}$, maternal circulating levels of calcium and $\mathrm{Pi}$, maternal or UCP levels of $25(\mathrm{OH}) \mathrm{D}$, and birth weight or placental weight might influence both the neonatal BMC and the UCP levels of $\alpha$-klotho, FGF23, and sclerostin or $25(\mathrm{OH}) \mathrm{D}$, we chose to include these variables in the analyses as potential confounders. The effect estimates for $\alpha$-klotho, FGF23, or $25(\mathrm{OH}) \mathrm{D}$ remained nonsignificant after adjustments for these confounding factors (Table 2).
In contrast, the effect of sclerostin on BMC was highly significant, also after adjustment.

In supplementary analyses, additional adjustments were performed for gestational age due to the assumption that the gestational age influenced both the BMC and the calcium metabolism. In these analyses, the independent direct effects of the UCP levels of $\alpha$-klotho, FGF23, and $25(\mathrm{OH}) \mathrm{D}$ on the BMC remained nonsignificant, whereas the effect of sclerostin was still significant (data not shown). 


\section{Discussion}

In this study, we demonstrated a significantly higher level of $\alpha$-klotho and sclerostin and significantly lower $25(\mathrm{OH}) \mathrm{D}$ values in the neonatal UCP compared with the maternal levels at weeks 32-34, whereas the mean FGF23 concentration was not significantly different between the babies and their mothers. Secondly, we showed that the neonatal total body BMC was significantly associated with the UCP levels of sclerostin, birth weight of the newborn, and the placental weight. However, the total body BMC could not be predicted by the maternal sclerostin values or circulating $\alpha$-klotho, FGF23, or 25(OH)D levels on either the maternal or the fetal side of the placenta.

A recent study suggested that $\alpha$-klotho was a biomarker for mineral metabolism in the fetus (12). The study showed that the soluble $\alpha$-klotho level in cord blood was significantly elevated, in accordance with our present study, and indicated that it may have originated from syncytiotrophoblasts in the placenta. Our finding that $\alpha$-klotho gene was expressed in placental tissue supports the notion of placental origin. However, it has not been determined whether the $\alpha$-klotho in the fetoplacental circulation could originate directly from the fetal tissues. The lower maternal levels of $\alpha$-klotho, which had been demonstrated previously (12), indicate a low production at the maternal site. However, it may also be due to a low release from the placenta to the maternal circulation or a rapid removal of the released $\alpha$-klotho.

Concerning FGF23, we could not demonstrate a difference between the neonatal UCP and maternal late gestational levels. Moreover, the FGF23 gene expression was not demonstrated in the placental tissue. Thus, our present data do not support a linkage between the plasma FGF2 3 concentrations and bone formation in neonates, as suggested by a recent study (10). They found that the concentration of total circulating FGF23 was high in healthy term infants, suggesting a more complex role of the FGF 23 cleavage process in neonatal mineral homeostasis.

We found a significantly higher level of sclerostin in the UCP compared with the maternal circulation, and a significant effect of UCP sclerostin on neonatal total body BMC. We were not able to demonstrate sclerostin gene expression in placental tissue. Our data indicate that sclerostin is produced in higher amounts in the newborn infant and positively related to bone mass. It could be speculated that the high sclerostin level was related to the delivery process by itself; however, the association to BMC indicates a more profound mechanism. Sclerostin is solely produced by osteocytes, the mechanoreceptors in the skeleton. Emerging evidence indicates that osteocytes regulate osteoblast function through the inhibitory protein sclerostin $(13,16,17)$; however, osteocytes may also be linked to bone resorption and osteoclastogenesis (29). Sclerostin levels are increased during immobilization and decreases following physical activation $(30,31)$. Our findings of high UCP sclerostin levels are in accordance with the weightless status of the fetus in utero with little strain on the bones despite movements. The association of sclerostin to BMC also indicates to other mechanisms to be explored. For example, unexpected high sclerostin levels were demonstrated in patients with high-bone mass phenotype due to a constitutive activation of the Wnt signaling pathway (32), thus indicating potential regulatory interactions.

The multiple regression models presented in Table 2 were restricted to the relationships between variables that are known from the literature and also to the variables from our study. Under these prerequisites, the multiple models represented the most likely models of variables that were assumed to influence both the levels of $\alpha$-klotho, FGF23, sclerostin, or 25(OH)D in the maternal circulation during late gestation and in the UCP at birth, and the infants' BMCs. However, the presented models have shortcomings in terms of unknown or unmeasured confounders and the lack of unknown indirect mechanisms.

Fetal growth is a result of multiple factors including the genetic potential for growth, maternal nutrition, maternal metabolism, endocrine factors, and placental perfusion and function $(1,33)$. In addition, the ability of the fetus to respond to nutrients and other growth regulatory factors may play a role. We identified birth weight as an independent predictor of the total body BMC in newborns. Birth weight has been associated with long-term effects on health and disease in adult life (34), and several epidemiological studies have shown relationships between growth in early life and the adult bone mass. Similar work in Bath (35) and Hertfordshire, UK (36), showed relationships between the weight at 1 year of age and the adult BMC, and recent studies have found evidence for an association between growth in early life and adult bone health $(37,38)$.

This study demonstrated that the placental weight was strongly associated with the neonatal BMC. Placental function is another potential major determinant of fetal growth in addition to glucose and other BMI-related factors. The placental function includes both transport capacity and endocrine and metabolic properties (39). In principle, maternal factors may affect fetal growth through two main pathways. One pathway may be independent of the placenta, i.e. maternal nutrients (and other factors) that enter the fetal circulation directly without any interference from the placental tissues. The second pathway affects fetal growth indirectly by modifying the placental nutritional transport and metabolism. Accordingly, the placental weight has been shown to be closely correlated with the birth weight in large studies (40).

Our study has limitations. The UCP is a mixture of venous and arterial blood, which makes any conclusion about the direct sources of $\alpha$-klotho, FGF23, sclerostin, 
or $25(\mathrm{OH}) \mathrm{D}$ at the fetal site difficult. The time from sampling of the UCP to freezing varied due to practical limitations in a busy delivery unit. However, according to the available information, none of these proteins exhibit an instability that requires immediate cooling or freezing. Whether the blood levels of $\alpha$-klotho, FGF23, sclerostin, or $25(\mathrm{OH}) \mathrm{D}$ may change as a consequence of maternal or fetal stress during delivery is unknown. Further, maternal samples obtained in weeks 30-32 might have changed during the following weeks of the last trimester.

In conclusion, we show that UCP sclerostin, placental weight, and birth weight are predictors of total bone mass in neonates. However, this study does not provide direct support for the hypothesis that maternal levels of sclerostin or the levels of $\alpha$-klotho, FGF23, or $25(\mathrm{OH}) \mathrm{D}$ in the fetal or maternal circulation play a main role for bone mass in the developing skeleton.

\section{Declaration of interest}

The authors declare that there is no conflict of interest that could be perceived as prejudicing the impartiality of the research reported.

\section{Funding}

Funding was obtained from the University of Oslo, thematic research area: Perinatal Nutrition and National Resource Center for Women's Health and Oslo Diabetes Research Center.

\section{References}

1 Henriksen T. Foetal nutrition, foetal growth restriction and health later in life. Acta Paediatrica. Supplement $1999 \mathbf{8 8} 4-8$. (doi:10.1111/j.1651-2227.1999.tb01284.x)

2 Kovacs CS \& Kronenberg HM. Maternal-fetal calcium and bone metabolism during pregnancy, puerperium, and lactation. Endocrine Reviews 199718 832-872. (doi:10.1210/er.18.6.832)

3 Care AD. The placental transfer of calcium. Journal of Developmental Physiology 199115 253-257.

4 Hosking DJ. Calcium homeostasis in pregnancy. Clinical Endocrinology 199645 1-6. (doi:10.1111/j.1365-2265.1996. tb02052.x)

5 Gallacher SJ, Fraser WD, Owens OJ, Dryburgh FJ, Logue FC, Jenkins A, Kennedy J \& Boyle IT. Changes in calciotrophic hormones and biochemical markers of bone turnover in normal human pregnancy. European Journal of Endocrinology 1994131 369-374. (doi:10.1530/eje.0.1310369)

6 Ritchie LD, Fung EB, Halloran BP, Turnlund JR, Loan MDV, Cann CE \& King JC. A longitudinal study of calcium homeostasis during human pregnancy and lactation and after resumption of menses. American Journal of Clinical Nutrition 199867 693-701.

7 Yamaga A, Taga M, Minaguchi H \& Sato K. Changes in bone mass as determined by ultrasound and biochemical markers of bone turnover during pregnancy and puerperium: a longitudinal study. Journal of Clinical Endocrinology and Metabolism 199681 752-756. (doi:10.1210/jc.81.2.752)

8 Riminucci M, Collins MT, Fedarko NS, Cherman N, Corsi A, White KE, Waguespack S, Gupta A, Hannon T, Econs MJ et al. FGF-23 in fibrous dysplasia of bone and its relationship to renal phosphate wasting. Journal of Clinical Investigation 2003112 683-692. (doi:10.1172/JCI18399)
9 Berndt T \& Kumar R. Phosphatonins and the regulation of phosphate homeostasis. Annual Review of Physiology 200769 341-359. (doi:10.1146/annurev.physiol.69.040705.141729)

10 Takaiwa M, Aya K, Miyai T, Hasegawa K, Yokoyama M, Kondo Y, Kodani N, Seino Y, Tanaka H \& Morishima T. Fibroblast growth factor 23 concentrations in healthy term infants during the early postpartum period. Bone 201047 256-262. (doi:10.1016/j.bone. 2010.05.024)

11 Kuro-o M, Matsumura Y, Aizawa H, Kawaguchi H, Suga T, Utsugi T, Ohyama Y, Kurabayashi M, Kaname T, Kume E et al. Mutation of the mouse klotho gene leads to a syndrome resembling ageing. Nature 1997390 45-51. (doi:10.1038/ 36285)

12 Ohata Y, Arahori H, Namba N, Kitaoka T, Hirai H, Wada K, Nakayama M, Michigami T, Imura A, Nabeshima YI et al. Circulating levels of soluble $\{\alpha\}$-klotho are markedly elevated in human umbilical cord blood. Journal of Clinical Endocrinology and Metabolism 201196 E943-E947. (doi:10.1210/jc.2010-2357)

13 Dijke PT, Krause C, de Gorter DJ, Lowik CW \& van Bezooijen RL. Osteocyte-derived sclerostin inhibits bone formation: its role in bone morphogenetic protein and Wnt signaling. Journal of Bone and Joint Surgery. American Volume 200890 (Suppl 1) 31-35. (doi:10.2106/JBJS.G.01183)

14 Wesenbeeck LV, Cleiren E, Gram J, Beals RK, Benichou O, Scopelliti D, Key L, Renton T, Bartels C, Gong Y et al. Six novel missense mutations in the LDL receptor-related protein 5 (LRP5) gene in different conditions with an increased bone density. American Journal of Human Genetics $2003 \quad \mathbf{7 2}$ 763-771. (doi:10.1086/368277)

15 Balemans W, Ebeling M, Patel N, Hul EV, Olson P, Dioszegi M, Lacza C, Wuyts W, Ende JVD, Willems P et al. Increased bone density in sclerosteosis is due to the deficiency of a novel secreted protein (SOST). Human Molecular Genetics 200110 537-543. (doi:10.1093/hmg/10.5.537)

16 Silverman SL. Sclerostin. Journal of Osteoporosis 201029 1-3. (doi:10.4061/2010/941419)

17 Krause C, Korchynskyi O, Rooij KD, Weidauer SE, de Gorter DJ, van Bezooijen RL, Hatsell S, Economides AN, Mueller TD, Lowik CW et al. Distinct modes of inhibition by sclerostin on bone morphogenetic protein and Wnt signaling pathways. Journal of Biological Chemistry $2010 \quad 285$ 41614-41626. (doi:10.1074/jbc.M110.153890)

18 Godang K, Qvigstad E, Voldner N, Isaksen GA, Froslie KF, Notthellen J, Henriksen T \& Bollerslev J. Assessing body composition in healthy newborn infants: reliability of dual-energy X-ray absorptiometry. Journal of Clinical Densitometry 201013 151-160. (doi:10.1016/j.jocd.2010.01.121)

19 Voldner N, Froslie KF, Bo K, Haakstad L, Hoff C, Godang K, Bollerslev J \& Henriksen T. Modifiable determinants of fetal macrosomia: role of lifestyle-related factors. Acta Obstetricia et Gynecologica Scandinavica $2008 \quad 87$ 423-429. (doi:10.1080/ $00016340801989825)$

20 Slattery MM \& Morrison JJ. Preterm delivery. Lancet 2002360 1489-1497. (doi:10.1016/S0140-6736(02)11476-0)

21 Gately PJ, Radley D, Cooke CB, Carroll S, Oldroyd B, Truscott JG, Coward WA \& Wright A. Comparison of body composition methods in overweight and obese children. Journal of Applied Physiology 200395 2039-2046. (doi:10.1152/japplphysiol. 00377.2003)

22 Yamazaki Y, Okazaki R, Shibata M, Hasegawa Y, Satoh K, Tajima T, Takeuchi Y, Fujita T, Nakahara K, Yamashita T et al. Increased circulatory level of biologically active full-length FGF-23 in patients with hypophosphatemic rickets/osteomalacia. Journal of Clinical Endocrinology and Metabolism $2002 \mathbf{8 7}$ 4957-4960. (doi:10.1210/jc.2002-021105)

23 Yamazaki Y, Imura A, Urakawa I, Shimada T, Murakami J, Aono Y, Hasegawa H, Yamashita T, Nakatani K, Saito Y et al. Establishment of sandwich ELISA for soluble $\alpha$-klotho measurement: age-dependent change of soluble $\alpha$-klotho levels in healthy subjects. Biochemical and Biophysical Research Communications 2010398 513-518. (doi:10.1016/j.bbrc.2010.06.110) 
24 Hernan MA, Hernandez-Diaz S, Werler MM \& Mitchell AA. Causal knowledge as a prerequisite for confounding evaluation: an application to birth defects epidemiology. American Journal of Epidemiology 2002155 176-184. (doi:10.1093/aje/155.2. 176)

25 Akcakus M, Koklu E, Kurtoglu S, Kula M \& Koklu SS. The relationship among intrauterine growth, insulinlike growth factor I (IGF-I), IGF-binding protein-3, and bone mineral status in newborn infants. American Journal of Perinatology 200623 473-480. (doi:10.1055/s-2006-954822)

26 Javaid MK, Godfrey KM, Taylor P, Shore SR, Breier B, Arden NK \& Cooper C. Umbilical venous IGF-1 concentration, neonatal bone mass, and body composition. Journal of Bone and Mineral Research 200419 56-63. (doi:10.1359/jbmr.0301211)

27 Godfrey K, Walker-Bone K, Robinson S, Taylor P, Shore S, Wheeler T \& Cooper C. Neonatal bone mass: influence of parental birthweight, maternal smoking, body composition, and activity during pregnancy. Journal of Bone and Mineral Research 200116 1694-1703. (doi:10.1359/jbmr.2001.16.9.1694)

28 L'Abee C, Vrieze I, Kluck T, Erwich JJ, Stolk RP \& Sauer PJ. Parental factors affecting the weights of the placenta and the offspring. Journal of Perinatal Medicine 201139 27-34. (doi:10.1515/jpm. 2010.119)

29 O'Brien CA, Nakashima T \& Takayanagi H. Osteocyte control of osteoclastogenesis. Bone 2013. In Press.

30 Gaudio A, Pennisi P, Bratengeier C, Torrisi V, Lindner B, Mangiafico RA, Pulvirenti I, Hawa G, Tringali G \& Fiore CE. Increased sclerostin serum levels associated with bone formation and resorption markers in patients with immobilization-induced bone loss. Journal of Clinical Endocrinology and Metabolism 201095 2248-2253. (doi:10.1210/jc.2010-0067)

31 Rubin J \& Rubin C. Stand UP. Journal of Clinical Endocrinology and Metabolism 201095 2050-2053. (doi:10.1210/jc.20100608)

32 Frost M, Andersen T, Gossiel F, Hansen S, Bollerslev J, Van Hul W, Eastell R, Kassem M \& Brixen K. Levels of serotonin, sclerostin, bone turnover markers as well as bone density and microarchitecture in patients with high-bone-mass phenotype due to a mutation in Lrp5. Journal of Bone and Mineral Research 2011 26 1721-1728. (doi:10.1002/jbmr.376)

33 Cetin I, Alvino G, Radaelli T \& Pardi G. Fetal nutrition: a review. Acta Paediatrica. Supplement 200594 7-13. (doi:10.1080/ 08035320510043709)

34 Barker DJ. The long-term outcome of retarded fetal growth. Clinical Obstetrics and Gynecology 199740 853-863. (doi:10.1097/ 00003081-199712000-00019)

35 Cooper C, Cawley M, Bhalla A, Egger P, Ring F, Morton L \& Barker D. Childhood growth, physical activity, and peak bone mass in women. Journal of Bone and Mineral Research 199510 940-947. (doi:10.1002/jbmr.5650100615)

36 Cooper C, Fall C, Egger P, Hobbs R, Eastell R \& Barker D. Growth in infancy and bone mass in later life. Annals of the Rheumatic Diseases 199756 17-21. (doi:10.1136/ard.56.1.17)

37 Baird J, Kurshid MA, Kim M, Harvey N, Dennison E \& Cooper C. Does birthweight predict bone mass in adulthood? A systematic review and meta-analysis Osteoporosis International 201122 1323-1334. (doi:10.1007/s00198-010-1344-9)

38 Tandon N, Fall CH, Osmond C, Sachdev HP, Prabhakaran D, Ramakrishnan L, Dey Biswas SK, Ramji S, Khalil A, Gera T et al. Growth from birth to adulthood and peak bone mass and density data from the New Delhi Birth Cohort. Osteoporosis International 201223 2447-2459. (doi:10.1007/s00198-011-1857-x)

39 Fowden AL, Ward JW, Wooding FP, Forhead AJ \& Constancia M. Programming placental nutrient transport capacity. Journal of Physiology 2006572 5-15. (doi:10.1113/jphysiol.2005.104141)

40 Salafia CM, Zhang J, Charles AK, Bresnahan M, Shrout P, Sun W \& Maas EM. Placental characteristics and birthweight. Paediatric and Perinatal Epidemiology 200822 229-239. (doi:10.1111/j.13653016.2008.00935.x)

Received 18 June 2012

Revised version received 30 November 2012

Accepted 6 December 2012 